\title{
Investigation of the Effects of Erosion Test Parameters on the Particle Impengement Velocity by Using CFD Analysis
}

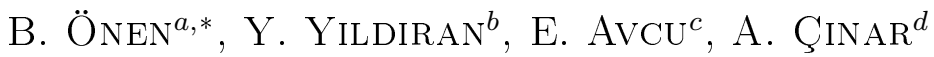 \\ ${ }^{a}$ Kocaeli University, Schools of Civil Aviation, 41285 Kocaeli, Turkey \\ ${ }^{b}$ Kocaeli University, Mechanical Eng. Dept., 41380 Kocaeli, Turkey \\ ${ }^{c}$ Kocaeli University, Ford Otosan İhsaniye Automotive Vocational School, 41680 Kocaeli, Turkey \\ ${ }^{d}$ Kocaeli University, Automotive Eng. Dept., 41380 Kocaeli, Turkey
}

\begin{abstract}
Particle impingement velocity is one of the most important parameters in solid particle erosion. Particle impingement velocity depends on erosion test parameters such as particle acceleration pressure, erodent particle size and standoff distance. Over the past decades many experimental studies have been conducted to examine the effects of these parameters on the particle impingement velocity. In this study, the effects of particle acceleration pressure, erodent particle size and standoff distance on the particle impingement velocity have been investigated by using a computational fluid dynamics (CFD) program, FLUENT. In order to achieve these goals solid particle erosion tests are simulated under various test parameters and the effects of these parameters are examined in detail. The effect of particle velocity on the flow field is characterized with method geometrics. Two-dimensional plane symmetrical models are utilized to reduce the computation time. Plots of gas pressure and particle velocity contours at the XY symmetrical plane from nozzle inlet to substrate were given. CFD analysis showed that all erosion test parameters have dramatically affected particle impingement velocity. Particle impingement velocity was increased with increases in acceleration pressure while it was decreased with increases in both erodent particle size and standoff distance.
\end{abstract}

DOI: $10.12693 /$ APhysPolA.127.1225

PACS: 45.50.Dd, 47.60.Kz, 07.05.Tp, 47.80.Jk

\section{Introduction}

Solid particle erosion (SPE) is a process of progressive removal of material from a target surface due to repeated impact of erodent particles. In some cases SPE is a useful phenomenon, as in sandblasting, high speed abrasive water jet cutting, grit blasting, shot peening etc., however it is a critical problem in various engineering systems, including steam and jet turbines, aircraft applications such as radar dome, pipelines and valves carrying particulate matter, and fluidized bed combustion systems [1]. SPE is specifically observed in pneumatic transportation of coal dust, gas turbines and surface finishing of machine parts where sand, grit or shot blasting process [2]. Particle impingement velocity can be considered as one of the most important parameters for many processes such as solid particle erosion, grit blasting, cold spray plasma coating, thermal spray coating and etc. [3-6]. Therefore, several methods such as laser doppler velocimeter, photographic technique, double disc method etc. have been used in order to measure the particle velocity [7]. Several parameters affect particle impingement velocity and it is highly important to understand the effects of these parameters on the velocity of impingement particles. Zeng et. al reported that nozzle geometry, properties of accelerating gas and particles affect particle impingement

* corresponding author; e-mail: barisonen@hotmail.com velocity. $\mathrm{Li}$ et al. also reported that nozzle geometry significantly influences the particle velocity.

As it is difficult to understand how the operational parameters (such as acceleration pressure, standoff distance, properties of impingement particle etc.) and design factors (such as nozzle length, nozzle geometry etc.) affect the particle impingement velocity, many researchers have tried to develop models [7] and apply computational simulations in order to analyze the particle impingement velocity [3-8]. The computational fluid dynamics (CFD) has made it possible to simulate gas-solid two-phase flow and analyze the particle impingement velocity as stated in literature $[3,5,9]$. Hence, many researchers have tried to analyze the effects of various parameters on the particle impingement velocity by using CFD analysis. Grewal et al. studied the effects of nozzle length on the velocity of impingement particles by using CFD analysis and reported that inadequate travel distance available for the erodent particles to accelerate to the velocity of the fluid stream could devoid the assumption that erodent particles travel at the velocity of fluid thus CFD could successfully be used to estimate and optimize the length of an acceleration tube [9]. It has been widely accepted that particle velocity prior to impact is one of the most important parameters of cold spraying. According to the reported results obtained by both the experiment and numerical simulation, many factors influence the particle velocity in cold spraying, including nozzle geometry, accelerating gas conditions and properties of particles [7]. Li et al. investigated the effect of standoff distance on coating deposition characteristic 
through both the experiment and CFD simulation of particle acceleration aiming at the optimization of cold spray process [10]. Azimian et al. examined experimental and CFD simulation of erosion wear of two hard metals in water-sand slurry mixture in a cylindrical tank tester and studying the dependence of erosion wear to influencing parameters [11].

Literature survey have showed that CFD analysis can be used in order to examine particle impingement velocity in various processes such as solid particle erosion, slurry erosion, cold spray coating etc. On the other it is important to address the effects of particle acceleration pressure, erodent particle size and standoff distance on the particle impingement velocities in these processes. Therefore, it is aimed to investigate the effects of particle acceleration pressure, erodent particle size and standoff distance on the particle impingement velocities in solid particle erosion process by using a (CFD) analysis. In order to achieve these goals solid particle erosion tests are simulated under various test parameters and the effects of these parameters are examined in detail.

\section{Experimental}

\subsection{Erodent particle characterization}

In this study it is aimed to simulate solid particle erosion under various parameters by using CFD analysis. The parameters of the simulation are selected to suit experimental studies previously presented by the researchers [12]. Hence, commercially available 20-40, 80, 120 and 180 mesh sized garnet particles are supplied and the average particle sizes of these particles are analyzed by using a laser diffraction particle size analyzer (Microtrack S3500). In Table the average particle size of garnet particles are given. Afterwards measured average particle sizes of garnet particles are used as the particle sizes in numerical modeling.

Average particle sizes of garnet par- TABLE ticles modeled in this study.

\begin{tabular}{c|c}
\hline \hline $\begin{array}{c}\text { Commercially used } \\
\text { garnet particles }\end{array}$ & $\begin{array}{c}\text { Measured average } \\
\text { particle sizes }\end{array}$ \\
\hline $20-40$ mesh & $702 \mu \mathrm{m}$ \\
80 mesh & $238 \mu \mathrm{m}$ \\
120 mesh & $206 \mu \mathrm{m}$ \\
180 mesh & $158 \mu \mathrm{m}$
\end{tabular}

\subsection{Numerical modeling}

In this study, numerical modeling was performed by using a ANSYS FLUENT program in order to determine the investigate the effects of standoff distance, acceleration pressure and particle size on the solid particle erosion process. Two-dimensional plane symmetrical models are utilized to reduce the computation time.

The nozzle inlet and outlet surfaces are schematically given in Fig. 1. In order to determine boundary conditions pressure inlet (actual operating pressure) and pressure outlet (correspondent to static atmospheric conditions) values were set up. In order to impose realistic

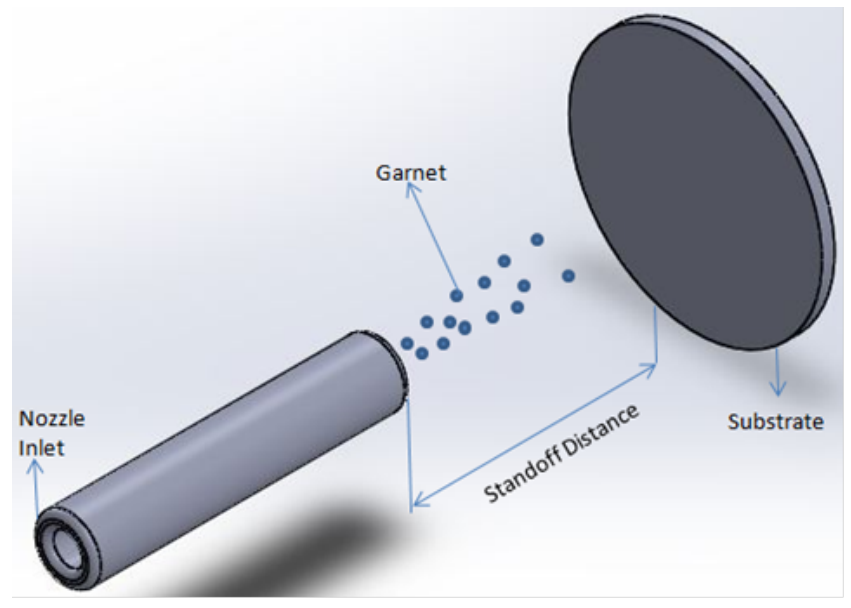

Fig. 1. Schematic diagram of the geometric model used in CFD analysis.

results the outlet boundary conditions have to be far enough from the nozzle exit cross-section [13], hence the outside domain was modeled with a cylinder of $50 \mathrm{~mm}$ in radius and $100 \mathrm{~mm}$ in length from the nozzle exit. The substrate was modeled as a rigid surface at the standoff distance from the nozzle exit location. The wall boundary is set as default in FLUENT which is a fixed heat flux of zero. The substrate was a disc of $20 \mathrm{~mm}$ in radius and $2 \mathrm{~mm}$ in thickness. The dimensions of nozzle in CFD analysis were a cylinder of $5 \mathrm{~mm}$ in radius and $50 \mathrm{~mm}$ in length. The governing equations for gas flow include the physical laws of conservation of mass, momentum, and energy. Because the coupled scheme obtains a robust and efficient single phase implementation for steady-state flows, a coupled implicit method is used to solve the flow field and the result of flow field in a steady state is obtained [4]. The realizable $K-\varepsilon$ turbulence model was utilized in the simulation because of the high pressure gradients [14]. The standard wall function is chosen for the near-wall flow treatment $[3,4,6,10]$.

Garnet is used as the erodent particle material. The acceleration of particles is computed using discrete phase modeling (DPM). The model requires that the discrete phase must be present at sufficiently low volume fractions. In this case, all the erodent particles are spherical in shape and hence the spherical drag law is used to compute the drag coefficient. Particle-particle interactions and the effect of particles on the gas phase can be neglected [4].

\section{Results and discussions}

\subsection{Effect of standoff distance on particle velocity}

Numerical simulations have been performed for Garnet particles of different sizes $(158 \mu \mathrm{m}, 206 \mu \mathrm{m}, 238 \mu \mathrm{m}$, $702 \mu \mathrm{m}$ ) according to the blasting nozzle conditions in this study. The acceleration gas was operated at pressures of 1.5 bar, 3 bar, 4 bar. The standoff distances from the nozzle exit to the substrate surface were 20,50 , 

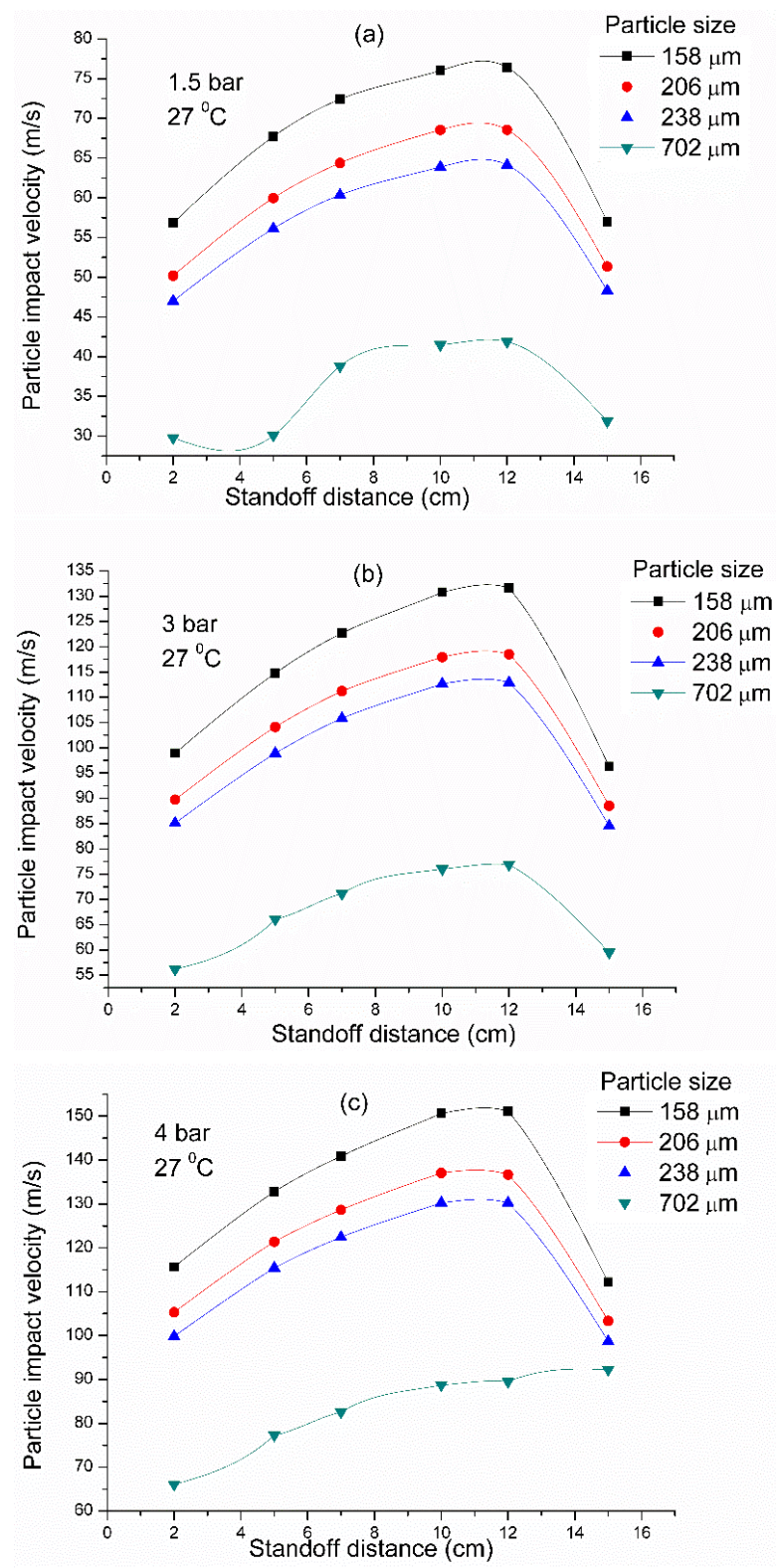

Fig. 2. The effect of standoff distance on the particle velocity under various parameters (a) 1.5 bar, (b) 3 bar, (c) 4 bar.

70, 100, 120, $150 \mathrm{~mm}$. Figure 2 shows the simulation results on the changes of particle velocities from nozzle to substrate surface at a acceleration pressure of 1.5 bar (Fig. 2a); at 3 bar (Fig. 2b) and 4 bar (Fig. 2c) respectively. It is seen that the particle velocity increases a bit after the nozzle exit at all pressure as seen in Fig. 2a, b and $c$. The particle velocity is decreased quickly at some standoff distance of about $120 \mathrm{~mm}$. The impingement particle velocities increase remarkably after the nozzle exit and are further accelerated to a maximum value outside the exit at some standoff distance ranging from 20 to $120 \mathrm{~mm}$, which is dependent on the particle size and acceleration pressure. The standoff distance increases with increasing the particle size. These results suggest that for a lighter particle the optimal standoff distance is shorter, which is consistent with the reported results that the lighter particles are more readily influenced by the gas flow [10]. Figure 3 shows contours of gas and particle ve-
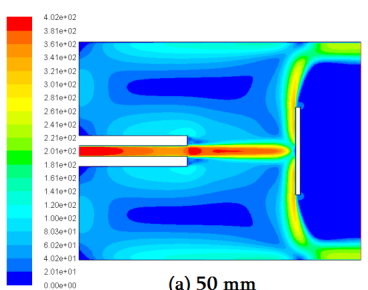

(a) $50 \mathrm{~mm}$

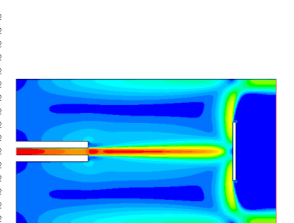

(c) $100 \mathrm{~mm}$

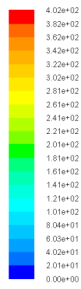

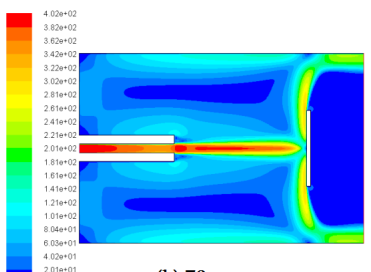

(b) $70 \mathrm{~mm}$

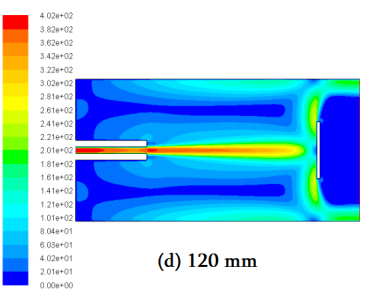

Fig. 3. Contours of gas and particle velocity $\left(\mathrm{ms}^{-1}\right)$ from nozzle inlet to substrate under various standoff distance (particle size: $206 \mu \mathrm{m}$, acceleration pressure: 3 bar).

locity from nozzle inlet to substrate under various standoff distances at $50 \mathrm{~mm}$ (Fig. 3a); at $70 \mathrm{~mm}$ (Fig. 3b); $100 \mathrm{~mm}$ (Fig. 3c) and $120 \mathrm{~mm}$ (Fig. 3d) respectively. The distributions of gas and particle velocity depending on the standoff distance can be clearly seen in Fig. 3 . Some shock waves are generated near the nozzle exit indicated by the oscillation of gas velocity. The velocities of gas and erodent particles decrease with increases in standoff distance which can be clearly seen in Fig. 3c. From Fig. 3 it can be concluded that standoff distance dramatically affect the velocities of gas and impingement particles. The velocity magnitude contours are well correlated with Fig. 2. These contours can be successfully used in order to understand the behavior of gas and particle velocity depending on standoff distance.

\subsection{Effect of particle acceleration pressure on the particle velocity}

In Fig. 4, the effect of particle acceleration pressure on the particle velocity under various parameters is given. The particle acceleration pressure significantly affects the particle velocity as seen in Fig. $4 \mathrm{a}$ and b.

The contours of the gas velocity magnitude obtained at three different gas stagnation pressures are presented in Fig. 5. It can be seen from the Fig. 5c that velocity of air at the exit of the nozzle was $\sim 450 \mathrm{~m} / \mathrm{s}$. In both cases, the gas flow is over-expanded with the typical diamondshock structure of the free jet [15]. In Fig. 5a, b and c it can be clearly seen that the gas and particle velocity are increased with augmentation in acceleration pressure. These results indicate that acceleration pressure greatly 

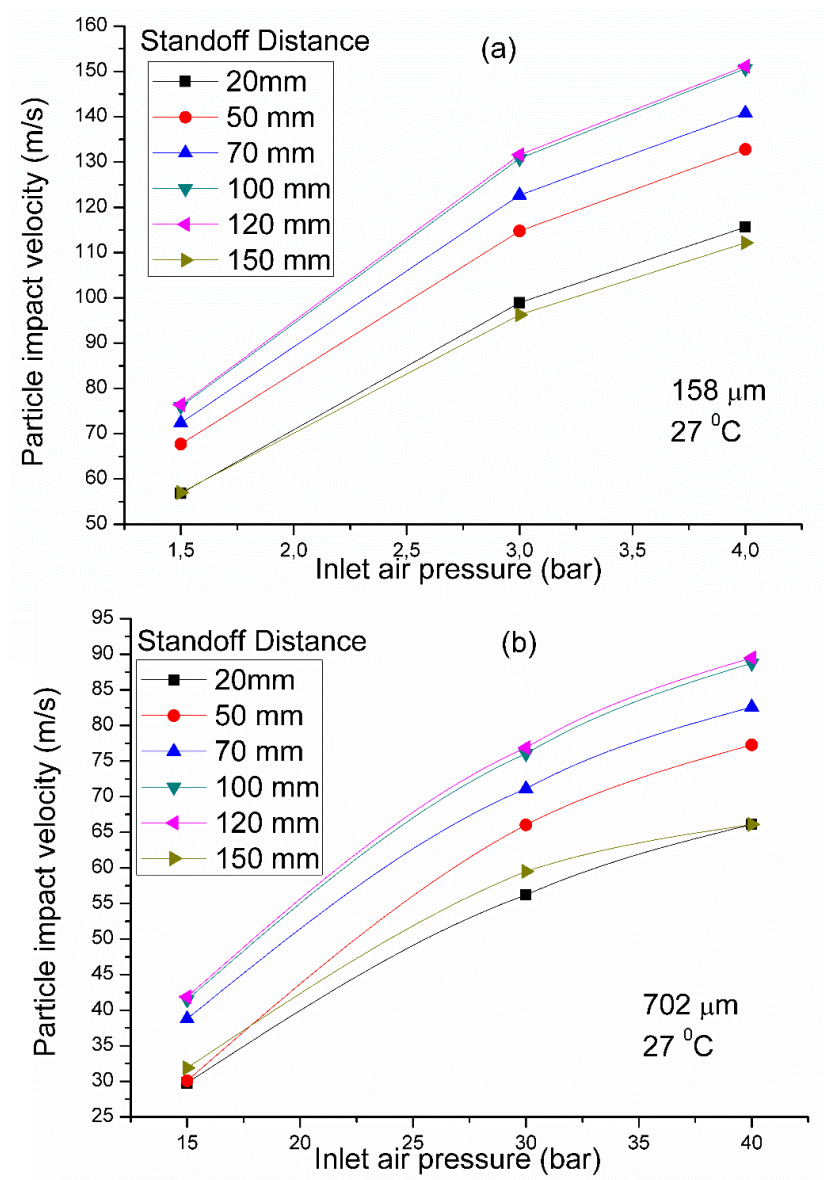

Fig. 4. The effect of particle Accelaration pressure on the particle velocity under various parameters.

affect the air and impingement particle velocities which is consistent with the reported results that as the inlet air pressure and airflow rate increase, the particle velocities also increase [7].

\subsection{Effect of particle size on particle velocity}

Distributions of garnet particle velocities depending on particle size along the nozzle axis obtained for three different values of gas stagnation pressures are presented in Fig. 6a, b and c. The calculation was performed for 158, 206, 238, $702 \mu \mathrm{m}$ sized particles. In Fig. 6 the particle velocity depends on the particle size and the gas stagnation pressure, and lies in the range between 40 and $80 \mathrm{~m} / \mathrm{s}$ at the point situated at $100 \mathrm{~mm}$ from the nozzle exit. Wang et al. [7] reported that the particle velocity decreases as the particle size increases and explained this by the increase of particle-particle and particle wall collisions. Li et al. [6] also reported that particle size significantly influences particle impingement velocity. $\mathrm{Li}[10]$ reported that impingement particle velocity increases with the decrease of particle size and higher particle velocity can be obtained with small sized particles. As it can be seen in Fig. 6a, b and $c$ the smallest

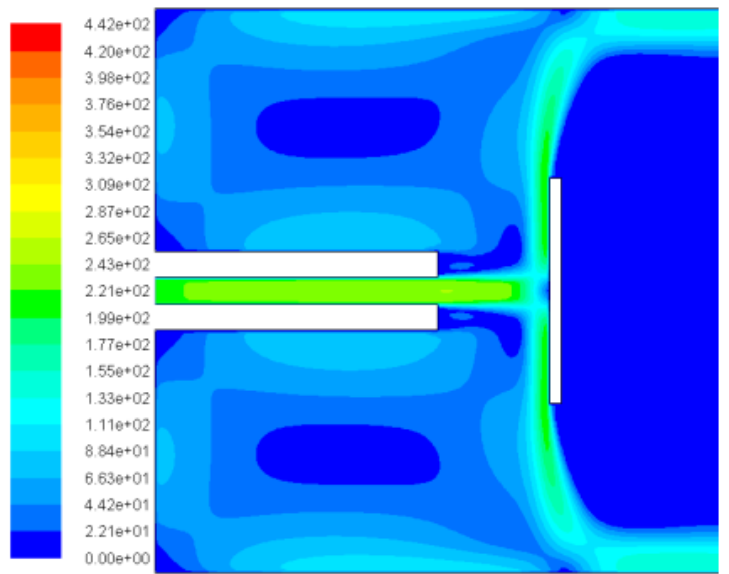

(a) 1.5 bar

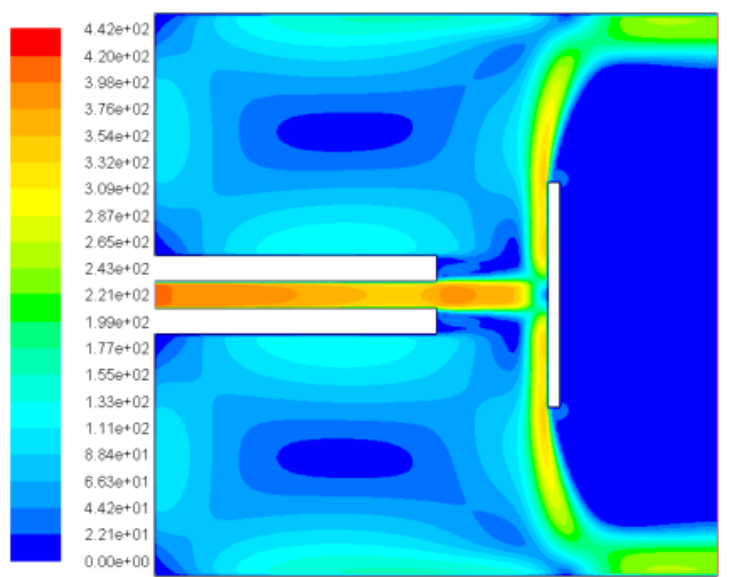

(b) 3 bar

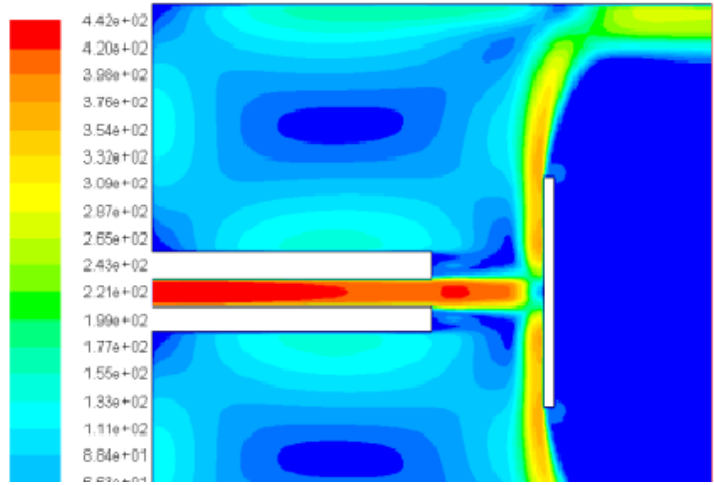

Fig. 5. Contours of gas and particle velocity $\left(\mathrm{m} \mathrm{s}^{-1}\right)$ from nozzle inlet to substrate under various acceleration pressure (particle size: $206 \mu \mathrm{m}$, standoff distance: $2 \mathrm{~mm})$.

garnet particles are always have the maximum particle impingement velocities, while the biggest garnet particles have the minimum. Hence, it can be concluded that the particle impingement velocity increases with the decrease in particle size as stated in literature $[6,7,10]$. 

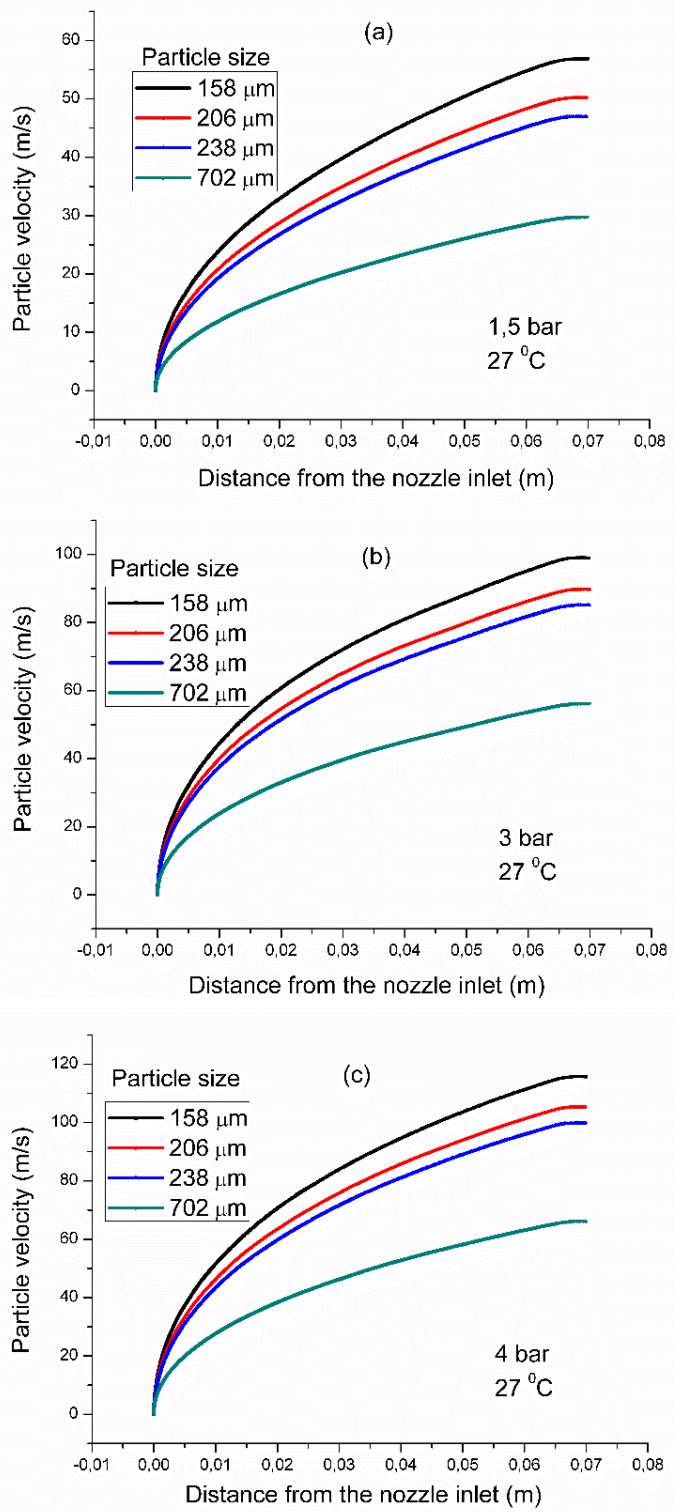

Fig. 6. The effect of particle size on the particle velocity under various parameters (a) 1.5 bar, (b) 3 bar, (c) 4 bar.

\section{Conclusions}

In this study, it is aimed to investigate the effects of particle acceleration pressure, erodent particle size and standoff distance on the particle impingement velocities in solid particle erosion process by using a (CFD) analysis. The conclusions of the study are given below.
All parameters have dramatically affected the particle impingement velocities. Plots of gas pressure and particle velocity contours at the XY symmetrical plane from nozzle inlet to substrate successfully demonstrate the variation of air and particle impingement velocities under various test parameters.

The impingement velocities of various sized particles are increased with increases in acceleration pressure. On the other hand the impingement velocities of particles are decreased with increases in particle size. Moreover, the impingement velocities of particles are increased with standoff distance up to a limit; however the impingement velocities are decreased with further increases beyond this limit.

Finally, it is concluded that the variation of particle impingement velocities under different parameters in solid particle erosion process can be successfully analyzed and investigated by using CFD analysis.

\section{References}

[1] A. Patnaik, A. Satapathy, N. Chand, N.M. Barkoula, S. Biswas, Wear 268, 249 (2010).

[2] K. Yildizlı, M.B. Karamış, F. Nair, Wear 261, 622 (2006).

[3] W.Y. Li, H. Liao, G. Douchy, C. Coddet, Materials and Design 28, 2129 (2007).

[4] S. Yin, X.F. Wang, W.Y. Li, Surface \& Coatings Technology 205, 2970 (2011).

[5] B. Samareh, O. Stier, V. Lüthen, A. Dolatabadi, Journal of Thermal Spray Technology 18, 934 (2009).

[6] W.Y. Li, C.J. Li, Journal of Thermal Spray Technology 14, 391 (2005).

[7] Q. Wang, M.C. Melaaen, S.R. De Silva, G. Tong, Powder Technology 160, 93 (2005).

[8] T. Deng, M.S. Bingley, M.S.A. Bradley, S.R. De Silva, Wear 265, 945 (2008).

[9] H.S Grewal., A. Agrawal, H. Singh, Journal of $\mathrm{Ma}$ terials Engineering and Performance 22, 152 (2013).

[10] W.Y. Li, C. Zhang, X.P. Guo, G. Zhang, H.L. Liao, C.J. Li, C. Coddet, Materials and Design 29, 297 (2008).

[11] M. Azimian, H.J. Bart, EPJ Web of Conferences 45, 01009 (2013).

[12] Y. Yildiran, E. Avcu, A.E. Şahin, S.Fidan, H. Yetiştiren, T. Sinmazçelik, Acta Physica Polonica A 125, 523 (2014).

[13] R. Lupoi, W. O'Neill, Surface \& Coatings Technology 206, 1069 (2011).

[14] R. Huang, H. Fukanuma, Journal of Thermal Spray Technology 21, 541 (2012).

[15] A. Sova, A. Okunkova, S. Grigoriev, I. Smurov, Journal of Thermal Spray Technology 22, 75 (2013). 